\title{
Effects of Temperature and Concentration on the Determination of PET Viscosity
}

\author{
Felipe Z. da Silva, ${ }^{\oplus * a}{ }^{*}$ Izabella C. Bastos ${ }^{a}$ and Daniela B. Hirata ${ }^{b}$ \\ anstituto de Ciência e Tecnologia (ICT), Universidade Federal de Alfenas (UNIFAL), \\ 37715-400 Poços de Caldas-MG, Brazil \\ ${ }^{b}$ Instituto de Química, Universidade Federal de Alfenas (UNIFAL), 37130-001 Alfenas-MG, Brazil
}

\begin{abstract}
This work describes the use of experiment planning to investigate the effects of the variables temperature and concentration of the polymer solution on the viscosity test of polyethylene terephthalate (PET). For this, the response surface methodology was based on a central composite rotatable design (CCRD) to optimize the combinations of the analytical conditions. With the analysis of the standard sample of PET with intrinsic viscosity of $0.630 \pm 0.008 \mathrm{dL} \mathrm{g}^{-1}$ and 2-chlorophenol solvent, it was observed that the solution flow temperature and PET concentration caused significant effects on the results, while the storage temperature of the solvent was not statistically significant. With the results and the model developed, an industrial solid state polymerization process of PET was evaluated with simulations of the production of 30 tons of PET, demonstrating the importance of controlling the variables to guarantee the performance in quality control laboratories.
\end{abstract}

Keywords: design of experiments, polyethylene terephthalate, viscosity

\section{Introduction}

Polymers are macromolecules obtained from the repetition of monomers in the process of polymerization. Polyethylene terephthalate (PET) was developed by the researchers Whinfield and Dickson in 1941, ${ }^{1}$ whose monomer can be synthesized by the direct esterification between terephthalic acid and ethylene glycol or transesterification between dimethyl terephthalate and ethylene glycol. In polymerization and solid state polymerization (SSP) steps for shaping the physicochemical properties of the material, certain process parameters must be continuously monitored to ensure product quality. ${ }^{2}$ The main characterization test of the resin and PET materials is the intrinsic viscosity (IV or $[\eta]$ ), in which the molar mass of the polymer is indirectly determined. . $^{3,4}$

In industrial processes, the results of material characterization are used as reference for adjustments in the reactors, such as distribution of residence time, temperature, pressure and operating flow. . $^{5}$

Some statistical techniques and tools have been used in engineering studies for process optimization, such as the planning of experiments (design of experiments, DOE).

*e-mail: fzaulisilva@gmail.com
When properly executed, this tool allows the management of people and projects and provides specific data for scientific and statistical application, ${ }^{9}$ in addition to being used in the development or improvement of products and detection of the effects of variables on processes. ${ }^{10,11}$

Although the design of experiments is a powerful tool for statistical investigations, its application at an industrial level is still not widespread. However, in recent years, some cases reported by the literature instigate the possibility of introducing this statistical technique in a range of processes, as performed by Fukuda et al. ${ }^{12}$ in the evaluation of quality control to obtain pharmaceutical compounds and Bowden et al. ${ }^{13}$ in the development and optimization of new radiochemical methods and the new synthesis of the PET tracker in copper-mediated radiofluorination (CMRF). Freitas et al. ${ }^{14}$ conducted a study, also using the design of experiments, to assess the effects of variables and stabilization additives in post-consumer PET, allowing simultaneous information to be obtained from the combination of the variables of interest.

Since the viscosity analysis of PET is dependent on variables with high sensitivity both in terms of control and in relation to the effects on the results, the requirements for performing the test need to be monitored to avoid detrimental deviations in industrial proportions. In summary, the temperature during the analysis and the 
polymer concentration in the diluted solution are essential factors for determining the viscosity. ${ }^{14}$

For the analysis of improvement and quality control in an industry of recycled PET resin production, located in the city of Poços de Caldas (Brazil), a statistical investigation was proposed to evaluate the effects of the variables on the results of intrinsic viscosity. In order to optimize the research, an experimental planning was used in the experimental design and, as the aim of the study, it was evaluated to develop an analytical model to predict the intrinsic viscosity and to highlight the impacts from this test in the processing line in cases of errors during the execution of the analyses. For this study only the analytical effects of the laboratory were considered, since the intrinsic viscosity of the materials tested were constant. The aim of the research was to present the sensitivity of the polymer solution (PET plus solvent) under the evaluated conditions.

\section{Experimental}

\section{Viscosity assay}

Analyses of the intrinsic viscosity were performed according to ASTM D2857, ${ }^{15}$ in which the polymer sample was dissolved in organic solvent and the relative viscosity (RV or $\eta_{\mathrm{r}}$ ) of this solution was analyzed relative to the pure solvent, using for this purpose a viscometer for the observation and measurement of the flow time. Relative viscosity can be converted to intrinsic viscosity by empirical models. In this work, the Billmeyer's and Huggins' model was adopted to perform this transformation..$^{15-17}$

For conducting the analyses, a standard sample of PET resin was used, with intrinsic viscosity of $0.630 \pm 0.008 \mathrm{dL} \mathrm{g}^{-1}$, previously dried in a convection oven at $120.0^{\circ} \mathrm{C}$ for $180 \mathrm{~min}$ (temperature for subsequent dissolution), and 2-chlorophenol (ortho-chlorophenol or OCP) with purity greater than $99 \%$ of the brand Sigma-Aldrich ${ }^{\circledR}$ (São Paulo, Brazil) as solvent for polymer dissolution. The solvent was stored in an amber bottle in an acrylic aquarium containing distilled water and PID (proportional, integral and derivative) temperature controller and the resin sample, in a hermetically sealed flask before drying.

\section{Design of the experiments (DOE)}

The standard condition of flow temperature, polymer concentration and storage temperature of the solvent were, respectively, $25.0{ }^{\circ} \mathrm{C}, 8.000 \mathrm{~g} \mathrm{dL}^{-1}$ and $25.0{ }^{\circ} \mathrm{C}$. Intervals of analysis were determined by means of central composite rotatable design (CCRD), shown in Table $1 .{ }^{10}$ The results were analyzed by the online software Protimiza Experimental Design. ${ }^{18}$

To evaluate the influence of the hygroscopicity of the PET resin on the weighing of material and due to the drying characteristics, moisture analysis was conducted in a convection oven for $180 \mathrm{~min}$ at $175.0^{\circ} \mathrm{C}$. The model generated was validated with analyses of the standard in intermediate conditions, in order to promote a scan of the internal points and to allow the creation of adjustment factors in future experiments..$^{1,19-25}$

\section{Effects of intrinsic viscosity on the industrial process}

For the application of the developed model, practical process simulations were carried out in an SSP industrial column of PET resin. Line feed consisted of amorphous PET resin from the extrusion of recycled PET flakes with intrinsic viscosity of $0.760 \pm 0.030 \mathrm{dL} \mathrm{g}^{-1}$ and exit of crystallized PET resin with viscosity of $0.820 \pm 0.030 \mathrm{dL} \mathrm{g}^{-1}$.

Solid state polymerization column consisted basically of a crystallizer, a dryer, solid state polymerization reactor with inert gas (nitrogen, $\mathrm{N}_{2}$ ) and the fluidized bed with air at atmospheric temperature $\left(<40.0{ }^{\circ} \mathrm{C}\right)$ for cooling, and had the function of raising the molar mass of the polymer (and consequently the intrinsic viscosity) for molding carbonated beverage containers and eliminating by-products such as ethylene glycol and acetaldehyde. ${ }^{1,19-22}$

A quality control laboratory evaluated the intrinsic viscosity of the PET inlet and outlet of the SSP process at $4 \mathrm{~h}$ intervals and only the material conforming to the appropriate specification was available for later commercialization. The daily production was 30 tons of post-condensed PET resin $\left(1250 \mathrm{~kg} \mathrm{~h}^{-1}\right)$. Figure 1 shows the simplified block diagram of the process.

With the validated model, the coefficients of the

Table 1. Independent variables and their levels for performing the assays

\begin{tabular}{lcccccc}
\hline \multirow{2}{*}{ Independent variable } & Symbol & \multicolumn{3}{c}{ Level } \\
\cline { 2 - 7 } & Coded & -1.68 & -1 & 0 & 1 & 1.68 \\
\hline Flow temperature $/{ }^{\circ} \mathrm{C}$ & $x_{1}$ & 23.3 & 24.0 & 25.0 & 26.0 & 26.7 \\
Polymer solution concentration $/\left(\mathrm{g} \mathrm{dL}^{-1}\right)$ & $x_{2}$ & 7.000 & 7.400 & 8.000 & 8.600 & 9.000 \\
Solvent storage temperature $/{ }^{\circ} \mathrm{C}$ & $x_{3}$ & 23.3 & 24.0 & 25.0 & 26.0 & 26.7 \\
\hline
\end{tabular}




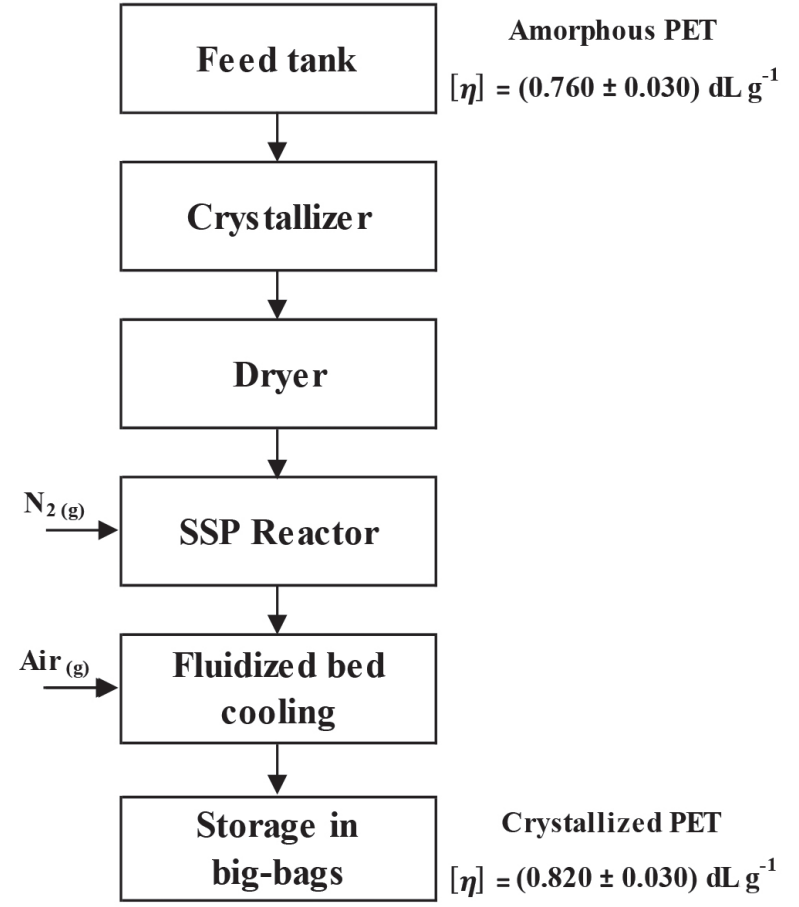

Figure 1. Simplified block diagram of the solid state polymerization (SSP) process of the recycled PET resin.

equation for the creation of a correction factor of emission of the results as a function of temperature were used, due to the facility of detecting their error in the execution of the analysis (for polymer concentration, the same could also be performed; however, the difficulty of perceiving the failure of this variable is greater because it is the first stage of the test).

\section{Results and Discussion}

Regression models for the responses

Table 2 shows the values and results of intrinsic viscosity of the adopted experimental design. To assure the results, the assays were performed in triplicate in each combination of the analytical conditions.

Equation 1 expresses the model with the variables coded for viscosity determination, which was obtained using statistically significant parameters for $p<0.05$. The terms that were not statistically significant were excluded from the model and added in the lack of fit for R-squared calculation. The coefficient determined was $99.62 \%$, which in this case was classified as excellent.

$[\eta]=0.630-0.017 x_{1}+0.050 x_{2}$

where $[\eta]$ is intrinsic viscosity.

It was verified that the model is of first order, linear and that the variable $\mathrm{x}_{3}$ (solvent storage temperature) was

Table 2. Matrix of the experimental design to investigate the effects of temperature and concentration variables on the polyethylene terephthalate (PET) viscosity assay

\begin{tabular}{|c|c|c|c|c|}
\hline \multirow{2}{*}{ Run } & \multicolumn{3}{|c|}{ Independent variable ${ }^{\mathrm{a}}$} & \multirow{2}{*}{$\frac{\text { Response }}{[\eta]^{\mathrm{b}} \pm \text { standard deviation } /\left(\mathrm{dL} \mathrm{g}^{-1}\right)}$} \\
\hline & $\mathrm{x}_{1}\left(\right.$ in $\left.{ }^{\circ} \mathrm{C}\right)$ & $\mathrm{x}_{2}\left(\right.$ in $\left.\mathrm{g} \mathrm{dL}^{-1}\right)$ & $\mathrm{x}_{3}\left(\right.$ in $\left.{ }^{\circ} \mathrm{C}\right)$ & \\
\hline 1 & $-1(24.0)$ & $-1(7.400)$ & $-1(24.0)$ & $0.595 \pm 0.001$ \\
\hline 2 & $1(26.0)$ & $-1(7.400)$ & $-1(24.0)$ & $0.561 \pm 0.001$ \\
\hline 3 & $-1(24.0)$ & $1(8.600)$ & $-1(24.0)$ & $0.700 \pm 0.001$ \\
\hline 4 & $1(26.0)$ & $1(8.600)$ & $-1(24.0)$ & $0.663 \pm 0.001$ \\
\hline 5 & $-1(24.0)$ & $-1(7.400)$ & $1(26.0)$ & $0.597 \pm 0.001$ \\
\hline 6 & $1(26.0)$ & $-1(7.400)$ & $1(26.0)$ & $0.562 \pm 0.002$ \\
\hline 7 & $-1(24.0)$ & $1(8.600)$ & $1(26.0)$ & $0.701 \pm 0.001$ \\
\hline 8 & $1(26.0)$ & $1(8.600)$ & $1(26.0)$ & $0.667 \pm 0.002$ \\
\hline 9 & $-1.68(23.3)$ & $0(8.000)$ & $0(25.0)$ & $0.652 \pm 0.001$ \\
\hline 10 & $1.68(26.7)$ & $0(8.000)$ & $0(25.0)$ & $0.600 \pm 0.001$ \\
\hline 11 & $0(25.0)$ & $-1.68(7.000)$ & $0(25.0)$ & $0.547 \pm 0.001$ \\
\hline 12 & $0(25.0)$ & $1.68(9.000)$ & $0(25.0)$ & $0.710 \pm 0.002$ \\
\hline 13 & $0(25.0)$ & $0(8.000)$ & $-1.68(23.3)$ & $0.625 \pm 0.001$ \\
\hline 14 & $0(25.0)$ & $0(8.000)$ & $1.68(26.7)$ & $0.634 \pm 0.001$ \\
\hline 15 (central point) & $0(25.0)$ & $0(8.000)$ & $0(25.0)$ & $0.630 \pm 0.002$ \\
\hline 16 (central point) & $0(25.0)$ & $0(8.000)$ & $0(25.0)$ & $0.630 \pm 0.001$ \\
\hline 17 (central point) & $0(25.0)$ & $0(8.000)$ & $0(25.0)$ & $0.629 \pm 0.002$ \\
\hline
\end{tabular}

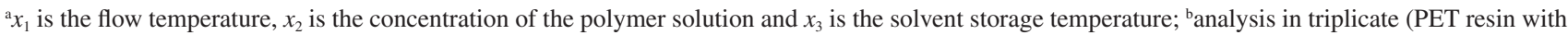
intrinsic viscosity of $0.630 \pm 0.008 \mathrm{dL} \mathrm{g}^{-1}$ at the central point). [ $\eta$ ]: intrinsic viscosity. 
Table 3. ANOVA of the polyethylene terephthalate (PET) viscosity assay

\begin{tabular}{|c|c|c|c|c|c|}
\hline Source of variation & Sum of squares & Degrees of freedom & Mean square & $F$-Test & $p$-Value \\
\hline Regression & 0.038571 & 2 & 0.01929 & & \\
\hline Residual & 0.000146 & 14 & 0.00001 & & \\
\hline Lack of fit & 0.000145 & - & - & 1846.30 & $1.10 \times 10^{-17}$ \\
\hline Pure error & 0.000001 & - & - & & \\
\hline Total & 0.038717 & 16 & - & & \\
\hline $\mathrm{R}^{2}=99.62 \%$ & $F_{2 ; 14 ; 0.05}=3.74$ & & & & \\
\hline
\end{tabular}

$\mathrm{R}^{2}$ : coefficient of determination.

not statistically significant in the interval studied. Table 3

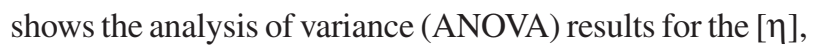
considering only the statistically significant terms. Based on the $F$-test, the model generated is more predictive and superior to the tabulated $F$ (3.74). ${ }^{10}$

Figure 2 shows that the experimental points were distributed around the diagonal line, indicating the excellent performance of the model. The variation of relative deviations was small $(<10 \%)$, representing the good fit of the model to the analytical points. Therefore, the coded model of equation 1 was used to generate the response surfaces for viscosity.

The analysis of the surface and response contour in Figure 2 indicates that the increase in temperature during flow and concentration of the polymer solution promoted an increase in intrinsic viscosity result, higher than the specification limit, while the storage temperature of the solvent only induced a deviation within the specified range of the standard sample used. The opposite effect is also observed in the viscosity with the decrease in the value of these variables.

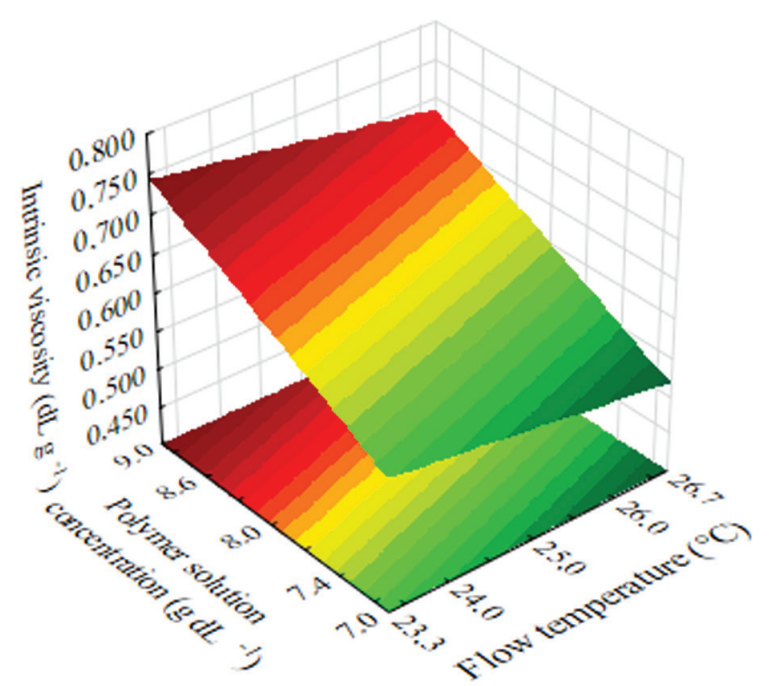

Figure 2. Response surface and contour diagram for the PET intrinsic viscosity assay.
The observed effects on viscosity due to flow temperature and polymer concentration have physical coherence. In liquid solutions, the viscosity is directly proportional to the force of attraction between molecules and, with increasing temperature, this force of attraction decreases, thus promoting the decrease of the resistance to flow. Thus, in liquids, the viscosity decreases with increasing temperature. ${ }^{23}$ However, the increase in polymer concentration in the solution causes the increase in viscosity, since the addition of new molecules promote intermolecular interactions that cause greater internal friction and consequent increase in the resistance to the flow. ${ }^{13}$

Additionally to the study, other factors were analyzed. PET resin pellets are a hygroscopic material from the processing point of view, and material hydrolysis may occur at high temperatures due to the breakdown of ester molecules. In this specific case of the study, the moisture evaluation was related to the effects of sample mass. ${ }^{24-26}$ When amorphous, the humidity of PET resin can reach, on average, up to $0.35 \% \mathrm{~m} / \mathrm{m}$ and, if crystallized, approximately $0.25 \% \mathrm{~m} / \mathrm{m} \cdot{ }^{12,20-26}$ As the sample weighing ranges were conventionally varied up to $0.001 \mathrm{~g}$, the moisture content became an important and necessary variable to be quantified to evaluate the possible effects on the standard weighings, which could have a direct impact on the concentrations in order to extrapolate the established limit.

By performing the procedure for moisture determination in triplicate, an average value of $0.040 \pm 0.009 \% \mathrm{~m} / \mathrm{m}$ was obtained. Considering the range of variation of the weighings, the presented moisture content resulted in a mass variation below the maximum limit tolerated for the execution of the weighings, which in general minimized this variable with respect to possible analytical errors of the study. ${ }^{27,28}$

Although the developed model presented an excellent correlation among the analytical points, for a better application of the results and the conclusions inherent to 
the study, a validation step was performed with intermediate points.

\section{Model validation}

The validation of the model of analysis consisted in selecting intermediate conditions of the statistically significant variables (keeping the variable $x_{3}$ in the central condition), predicting the value of intrinsic viscosity and comparison with the experimental result. Table 4 presents the tests performed and the relative deviations found.

It was found that the overall relative deviation of the validation was $<1 \%$, which was another indicative of the adequacy of the experimental points to the model generated.

It was decided to apply and determine the correction factor only for the variable flow temperature, since it can be monitored continuously during the analysis. However, polymer concentration may undergo diversified undesirable variations (weighing, solvent transfer and dissolution), which impedes the effective use of a correction element. Ranging between 23.3 and $26.7^{\circ} \mathrm{C}$, the corresponding temperature correction codes were created between -1.68 and 1.68 .

Equation 2, which contains the developed algebraic model, indicates that the coefficient related to the flow temperature is 0.017 . Thus, when multiplied by any of the correction codes, it will result in a portion that must be added to or subtracted from the value of [ $\eta]$ found at the temperature of the corresponding level. This operation allows the acquisition of the normalized result at $25.0^{\circ} \mathrm{C}$.

$[\eta]_{T=25.0^{\circ} \mathrm{C}}=[\eta]_{\mathrm{T}=\mathrm{i}}+0.017 \mathrm{~L}_{\mathrm{i}}$

where $[\eta]_{\mathrm{T}=25.0^{\circ} \mathrm{C}}$ is the intrinsic viscosity normalized to $25.0{ }^{\circ} \mathrm{C},[\eta]_{\mathrm{T}=\mathrm{i}}$ is the intrinsic viscosity with temperature flow $i$ and $L_{i}$ is the corresponding level (positive or negative).

Due to the specificities of the molecular chain of PET, the validity of the developed model needs to be validated for other groups of PET family, mainly for industrial grade samples. ${ }^{1,14,26}$ Thus, during model validation and comparison with production samples, the correlation between the studied parameters and the results with samples produced during processing were critically evaluated.

\section{Effects on the SSP process}

The process control in an SSP column should monitor parameters of temperature and polymer flow so that the adjustment of the molar mass (intrinsic viscosity) is in accordance with the specification and desired application, which relates mainly to the type of product to be stored in PET packaging. However, other variables also need to compose the control mesh, such as inert gas flow in the fluidized reactor, working pressure, degree of crystallization and residence time of the material., 529

In particular, the residence time distribution, which varies between 10 and $30 \mathrm{~h}$ according to the required product, is associated with the increase in PET viscosity and, for adjustments of this parameter, the regulation of the distribution may be effected from the viscosity results of the control laboratory in order to increase the process time in cases of viscosity below the lower specification limit. However, as an example of the studied process, errors of analysis can compromise an entire production period, since each result is obtained after 90 min at sampling intervals of $4 \mathrm{~h}$, and the process adjustments cause immediate impacts due to continuous production. ${ }^{1}$

The daily analyses of the production were carried out purposely with flow temperature of 23.5 and $26.5{ }^{\circ} \mathrm{C}$.

Table 4. Validation results of the model for viscosity analysis

\begin{tabular}{|c|c|c|c|c|c|}
\hline \multirow{2}{*}{ Run } & \multicolumn{2}{|c|}{ Independent variables $\mathrm{s}^{\mathrm{a}}$} & \multirow{2}{*}{ Predicted $[\eta] /\left(\mathrm{dL} \mathrm{g}^{-1}\right)$} & \multirow{2}{*}{ Result of $[\eta]^{\mathrm{b}} /\left(\mathrm{dL} \mathrm{g}^{-1}\right)$} & \multirow{2}{*}{ Relative deviation / \% } \\
\hline & $\mathrm{x}_{1}\left(\right.$ in $\left.{ }^{\circ} \mathrm{C}\right)$ & $\mathrm{x}_{2}\left(\right.$ in $\left.\mathrm{g} \mathrm{dL}^{-1}\right)$ & & & \\
\hline 1 & $-0.5(24.5)$ & $-0.5(7.700)$ & 0.614 & $0.615 \pm 0.002$ & 0.16 \\
\hline 2 & $0.5(25.5)$ & $0.5(8.300)$ & 0.647 & $0.643 \pm 0.003$ & -0.62 \\
\hline 3 & $-0.5(24.5)$ & $0.5(8.300)$ & 0.664 & $0.656 \pm 0.001$ & -1.22 \\
\hline 4 & $0.5(25.5)$ & $-0.5(7.700)$ & 0.597 & $0.602 \pm 0.002$ & 0.83 \\
\hline 5 & $-1.3(23.7)$ & $-1.3(7.200)$ & 0.587 & $0.596 \pm 0.002$ & 1.51 \\
\hline 6 & $1.3(26.3)$ & $1.3(8.800)$ & 0.673 & $0.665 \pm 0.002$ & -1.20 \\
\hline 7 & $-1.3(23.7)$ & $1.3(8.800)$ & 0.717 & $0.712 \pm 0.003$ & -0.70 \\
\hline 8 & $1.3(26.3)$ & $-1.3(7.200)$ & 0.543 & $0.545 \pm 0.004$ & 0.37 \\
\hline 9 & $0.0(25.0)$ & $0.0(8.000)$ & 0.630 & $0.631 \pm 0.002$ & 0.16 \\
\hline
\end{tabular}

${ }^{\mathrm{a}} \mathrm{X}_{1}$ is the flow temperature, $\mathrm{x}_{2}$ is the concentration of the polymer solution; ${ }^{\mathrm{b}}$ analysis in triplicate. [ $\eta$ ]: intrinsic viscosity. 
Table 5. Temperature correction factor in the viscosity analysis of polyethylene terephthalate (PET) resin

\begin{tabular}{lccccc}
\hline Run & {$[\eta]_{\mathrm{T}=23.5{ }^{\circ} \mathrm{C}}$} & {$[\eta]_{\text {normalized } \mathrm{T}=25.0{ }^{\circ} \mathrm{C}}{ }^{\mathrm{a}}$} & {$[\eta]_{\mathrm{T}=26.5{ }^{\circ} \mathrm{C}}$} & {$[\eta]_{\text {normalized } \mathrm{T}=25.0^{\circ} \mathrm{C}{ }^{\mathrm{a}}}$} & {$[\eta]_{\mathrm{T}=25.0{ }^{\circ} \mathrm{C}}$} \\
\hline 1 & 0.863 & 0.838 & 0.815 & 0.840 & 0.836 \\
2 & 0.859 & 0.834 & 0.808 & 0.833 & 0.835 \\
3 & 0.865 & 0.840 & 0.814 & 0.839 & 0.839 \\
4 & 0.856 & 0.831 & 0.807 & 0.832 & 0.829 \\
5 & 0.858 & 0.833 & 0.810 & 0.835 & 0.832 \\
6 & 0.853 & 0.828 & 0.805 & 0.830 & 0.827 \\
\hline
\end{tabular}

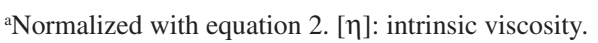

In parallel, the same analyses were also conducted at $25.0{ }^{\circ} \mathrm{C}$ to guarantee the quality of the PET resin. To normalize the results at $25.0^{\circ} \mathrm{C}$ of the analyses out of this value, equation 2 and the temperature correction codes were used. Table 5 shows the results and normalizations performed.

A critical analysis of the results in Table 5 reflects significantly in the process. It should be emphasized that the analyzed period comprises a daily production of 30 tons of PET resin. If the results emitted by the laboratory had been at $23.5^{\circ} \mathrm{C}$, the whole production would be segregated with a quality classification lower than the commercial standard (since in fact, the material would be under normal condition). As a side effect, unnecessary adjustments would be made to the process variables in order to achieve the specification. Analogously, at $26.5^{\circ} \mathrm{C}$, even at the wrong temperature, the production would not be disqualified; however, there would be a margin for false adjustments that would result in process lack of control.

In industrial quality control laboratories, the present study can be used for monitoring reference of the analytical variables of the PET intrinsic viscosity assay, since this is the main parameter to characterize the resin during its processing and subsequent application. ${ }^{30}$ In the case of the runoff temperature of the test, it was noted that small deviations (on the order of $0.1{ }^{\circ} \mathrm{C}$ ) are already sufficient to cause a change in the viscosity measure of the sample under evaluation.

\section{Conclusions}

The use of experimental design was proven advantageous in the investigation of the effects of the variables temperature and concentration of polymer solution in the viscosity test of PET. It was possible to verify that the storage temperature of the solvent 2-chlorophenol was not statistically significant in the analyses (within the study range between 23.3 and $26.7^{\circ} \mathrm{C}$ ), which indicates that if the solvent is in this thermal range there will be no significant deviations in the results. In this study it was found that the flow temperature and concentration of the polymer strongly impact the relative viscosity and consequently induces errors in reporting intrinsic viscosity.

\section{Acknowledgments}

This study was financed in part by the Coordenação de Aperfeiçoamento de Pessoal de Nível Superior (CAPES), Brazil, finance code 001.

\section{References}

1. Whinfield, J. R.; Dickson, J. T.; US pat. 2,465,319, 1949.

2. Mark, H. F.; Bikales, N. M.; Overberger, C. G.; Menges, G.; Kroschwitz, J. I.; Polyesters to Polypeptide Synthesis, Encyclopedia of Polymer Science and Engineering, $2^{\text {nd }}$ ed.; Wiley-Interscience: New York, USA, 1988.

3. Chang, S.; Sheu, M. F.; Chen, S. M.; J. Appl. Polym. Sci. 1983, $28,3289$.

4. Billmeyer, F. W.; Textbook of Polymer Science, $3^{\text {rd }}$ ed.; John Wiley \& Sons: New York, USA, 1984.

5. Yamada, T.; Polym. J. 1992, 24, 43.

6. Fogler, H. S.; Elementos de Engenharia das Reações Químicas, $4^{\text {th }}$ ed.; LTC: Rio de Janeiro, Brazil, 2009.

7. Madanhire, I.; Mbohwa, C.; Procedia CIRP 2016, 40, 580.

8. Li, J.; Papadopoulos, C. T.; Zhang, L.; Int. J. Prod. Res. 2016, 54,6281 .

9. Freeman, L. J.; Ryan, A. G.; Kensler, J. L. K.; Dickinson, R. M.; Vining, G. G.; Qual. Eng. 2013, 25, 315.

10. Rodrigues, M. I.; Iemma, A. F.; Experimental Design and Process Optimization; CRC Press: New York, USA, 2015.

11. Box, G. E. P.; Hunter, J. S.; Hunter, W. G.; Statistics for Experimenters: Design, Innovation, and Discovery; John Wiley \& Sons: New Jersey, USA, 2005.

12. Fukuda, I. M.; Pinto, C. F. F.; Moreira, C. S.; Saviano, A. M.; Lourenço, F. R.; Braz. J. Pharm. Sci. 2018, 54, e01006.

13. Bowden, G. D.; Pichler, B. J.; Maurer, A.; Sci. Rep. 2019, 9 , 11370. 
14. Freitas, F. L. S.; Chinellato, A. C.; Filho, E. R. P.; Cruz, S. A.; Polym. Test. 2020, 81, 106275.

15. ASTM D2857: Standard Practice for Dilute Solution Viscosity of Polymers; ASTM International, West Conshohocken, PA, 2016.

16. Visakh, P. M.; Liang, M.; Poly(Ethylene Terephthalate) Based Blends, Composites and Nanocomposites; Elsevier: London, UK, 2015.

17. Billmeyer, F. W.; J. Polym. Sci. 1949, 4, 83.

18. Rodrigues, M. I.; Costa, P.; Protimiza Experimental Design, v.1.0; Protimiza, Brazil, 2018.

19. Lobo, H.; Bonilla, J. V.; Handbook of Plastics Analysis; Marcel Dekker: New York, USA, 2003.

20. Whitehead, B. D.; Ind. Eng. Chem. Process Des. Dev. 1977, $16,341$.

21. Pó, R.; Occhiello, E.; Giannotta, G.; Pelosin, L.; Abis, L.; Polym. Adv. Technol. 1996, 7, 365.

22. Zhi, L. T.; Gao, Q.; Nan, X. H.; Sironi, C.; J. Appl. Polym. Sci. 1995, 57, 473.
23. Hibbeler, R. C.; Fluid Mechanics; Pearson Pumtke Hall: New York, USA, 2015.

24. Rosato, D. V.; Rosato, D. V.; Rosato, M. G.; Injection Molding Handbook, $3^{\text {rd }}$ ed.; Springer Science Business Media: New York, USA, 2000.

25. Elamri, A.; Abid, K.; Harzallah, O.; Lallam, A.; Am. J. Nano Res. Appl. 2015, 3, 11.

26. Fakirov, S.; Handbook of Thermoplastic Polymers: Homopolymers, Copolymers, Blends, and Composites, vol. 1; Wiley-VCH Verlag GmbH: Weinheim, Germany, 2002.

27. Ouchi, I.; Hosoi, M.; Tomie, T.; Jpn. J. Appl. Phys. 1992, 31, 2505.

28. Pirzadeh, E.; Zadhoush, A.; Haghighat, M.; J. Appl. Polym. Sci. 2007, 106, 1544.

29. Kemkes, J. F.; J. Polym. Sci. 1969, 22, 713.

30. Ma, Y.; Agarwal, U. S.; Sikkema, D. J.; Lemstra, P. J.; Polymer 2003, 44, 4085. 